\title{
南極・宗谷海岸での人工地震観測
}

$\begin{array}{lllll}\text { 名古屋大学理学部 伊 神 } & \text { 煇 } \\ \text { 国立極地研究所 神 沼 克 伊 } \\ \text { 東京大学地震研究所 一 , 瀬 洋 一 }\end{array}$

(昭和 55 年 6 月 27 日受理)

\section{Upper Crustal Structure of Soya Coast, Antarctica Revealed by Explosion Seismology}

\author{
Akira IKAMI \\ Faculty of Science, Nagoya University, Japan \\ Katsutada KAMINUMA \\ National Institute of Polar Research, Japan \\ and Yoichiro ICHINOSE \\ Earthquake Research Institute, Tokyo University, Japan \\ (Received June 27, 1980)
}

The summer-field party of the 20th Japanese Antarctic Research Expedition (JARE) carried out observations of explosion seismology to investigate the crustal structure of Soya Coast in Antarctica in January 1979. This was the first for JARE to carry out the explosion seismology for study on the crustal structure in Antarctica.

The objectives of the measurements by JARE-20 are to establish the techniques of explosion seismology in Antarctica, such as the laying of lines and instrumentation, development of ice drills, dynamite for the use at low temperatures, etc. JARE-21 will continue the observation along the $250 \mathrm{~km}$ measurement line during the winter of 1980 .

An upper crustal model is presented in this report. An overlaying thin layer of $4 \sim$ $5 \mathrm{~km} / \mathrm{s} \mathrm{P}$ wave volocity is firstly estimated in the structure model of East Antarctica.

\section{1. まえがき}

第 20 次南極地域観測隊 (1978-1980) の夏期オペレーションの1つとして人工地震実験が行 われた。これまで氷厚を求める目的で人工地震実験が行われたことがある $[\mathrm{ETO},(1971)] か ゙ ，$ 地殼構造を解明するために実施したのは，日本隊としては今回がはじめてである. 外国隊で も，氷厚を求めるための小規模な実験は何度も行われておりそそれらの結果は BENTLEY (1962) がまとめている.ソビエト隊は地殼構造を求める目的で測線長 $400 \mathrm{~km}$ の規模の観測を実施し ている [KOGAN, (1972)]. 
第 21 次隊では測線 $250 \mathrm{~km}$ の規模の実験が計画されており, 第 20 次隊としてはこのため (i) 南極における人工地震実験法の確立, (ii) 水床ボーリング装置の開発, (iii) 低温使用の可能 な観測装置およびダイナマイトの開発等を主目的として実験を実施した.

今回の観測を実施した測線のルートは途中まで，内陸のみず基地へのルートになつてお り, 過去に重力や標高の測定が行われている.この附近は海岸線に沿い所々に露岩がある.そ れらの露岩は大体カンブリア紀の花崗片麻岩が主であり, 人工地震実験地域の基盤岩も, 同じ ような地質構造と推定される.

\section{2. 観 測 概 要}

観測や氷床ボーリングのオペレーションについては，伊神他（1980）が詳細に報告している ので, ここでは概略についてのべる.

\section{2-1. 測線}

観測点は昭和基地の東方約 $20 \mathrm{~km}$ の大陸上の通称 S-16 点から東に $5 \mathrm{~km}$ 間隔で 10 点設 置した．爆破点はオングル海峡 (Shot-1) と東端の観測点のさらに $5 \mathrm{~km}$ 東の雪氷中 (Shot-2) である. 各観測点および爆破点の位置決定は次の様にした。

i） Shot-1：東オングル島の見晴岩を基準に方位と距離より地形図上にて経緯度を決定.

ii） 西端の観測点（観測点 No. 1)：人工衛星位置決定装置を用いて決定した．夏期行動期 間中は受信状態が悪く，越冬隊員によつて後日決定されたものを用いた。

iii) Shot-2: 天測によつて決定.

iv）その他の観測点：Shot-2 点を含めて全ての観測点で人工衛星位置決定装置を用いたが 受信状態が悪く, 雪上車の距離計により位置を決定せざるを得なかつた。2 台の雪上車で合計 4 往復したが，行動の際には距離計の読みを必ず記録していたので，その平均值をもとめた

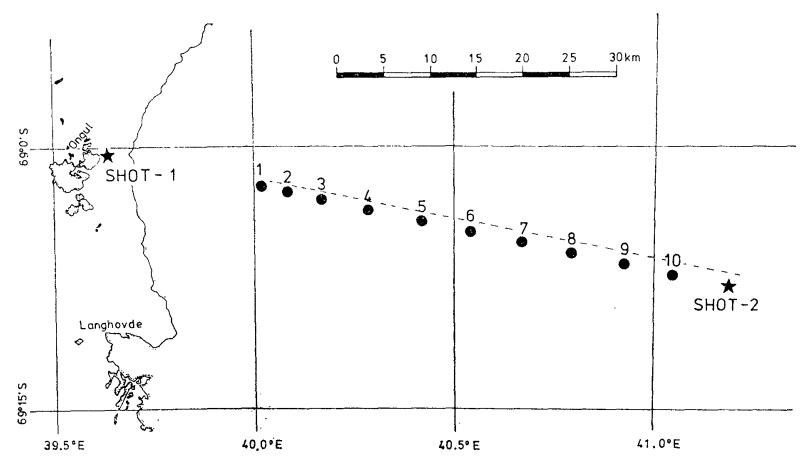

Fig. 1. Location for shot and observation sites. The dashed line is the traverse root used by Japanese Antarctic Research Expedition (JARE). 
Table 1. Locations of shot points, observation points and distances between them.

\begin{tabular}{|c|c|c|c|c|c|c|c|}
\hline \multirow{3}{*}{$\begin{array}{c}\begin{array}{c}\text { Shot and observation } \\
\text { point }\end{array} \\
\text { Shot-1 (Ongul Strait) }\end{array}$} & \multirow{2}{*}{\multicolumn{2}{|c|}{$\begin{array}{l}\text { Latitude } \\
\text { (S) }\end{array}$}} & \multirow{2}{*}{\multicolumn{2}{|c|}{$\begin{array}{l}\text { Longitude } \\
\text { (E) }\end{array}$}} & \multirow{3}{*}{$\begin{array}{l}\text { Elevation } \\
-124 \mathrm{~m}\end{array}$} & \multicolumn{2}{|c|}{ Distance from } \\
\hline & & & & & & \multirow[t]{2}{*}{ Shot-1 } & \multirow{2}{*}{$\begin{array}{l}\text { Shot-2 } \\
68.3 \mathrm{~km}\end{array}$} \\
\hline & 6900 & 27.9 & 3937 & 51.4 & & & \\
\hline No. 1 (S16) & 6901 & 46.7 & 4003 & 18.0 & 540 & $17.2 \mathrm{~km}$ & 51.3 \\
\hline No. 2 & 6902 & 16.5 & 4008 & 40.2 & 610 & 20.8 & 47.6 \\
\hline No. 3 & 6902 & 40.8 & 4013 & 01.5 & 660 & 23.8 & 44.6 \\
\hline No. 4 & 6903 & 27.2 & 4021 & 17.9 & 780 & 29.5 & 38.9 \\
\hline No. 5 & 6904 & 14.9 & 4029 & 43.0 & 900 & 35.3 & 33.1 \\
\hline No. 6 & 6905 & 01.1 & 4037 & 50.7 & 980 & 40.9 & 27.5 \\
\hline No. 7 & 6905 & 50.3 & 4046 & 24.6 & 1040 & 46.8 & 21.6 \\
\hline No. 8 & 6906 & 37.7 & .4054 & 32.3 & 1080 & 52.4 & 16.0 \\
\hline No. 9 & 6907 & 25.2 & 4102 & 40.0 & 1140 & 58.0 & 10.4 \\
\hline No. 10 & 6908 & 08.8 & 4110 & 04.2 & 1180 & 63.0 & 5.3 \\
\hline Shot-2 (Boring site) & 6908 & 54.5 & 4117 & 45.9 & 1220 & 68.3 & \\
\hline
\end{tabular}

(值のバラッキは $0.1 \mathrm{~km}$ ). No. 1 の観測点と Shot-2 の距離は (ii), (iii) より既知であるから, 上記平均值に比例配分して各観測点間の距離をもとめ，その值より経緯度を計算した．各観測 点間の位置の誤差は $100 \mathrm{~m}$ 以下になつていると思われる. 以上によつてもとめた爆破点, 観 測点の分布を Fig. 1 に示す. また Table 1 には爆破点, 観測点の経緯度と爆破点から観測 点をでの距離を示す.

\section{2-2. 観 測 計 器}

オペレーションに動員可能な人数には制限があり，計器は無人で動かす必要がある。このた めデータの収集には，(i) 各観測点にて長時間連続作動可能な記録方法，(ii）無線でデータを 1 ケ所にて集中記録，(iii) タイマーなどを用いて一定時間だけ現地で記録する方式，等が考えら れる. (ii) の場合 $-20^{\circ} \mathrm{C}$ の低温下で作動するテレメーターシステムを使うには，かなりのテ スト，準備期間が必要で，今回実施するのは困難であつた。 また (iii) は南極の厳しい自然条 件下でタイマーの設定通りに，全てのオペレーションを実行するには，多くの困難が予想され たので，今回は（i）の方法で実施した.

この方法は (ii), (iii) に比べ, 周波数特性が悪く, $\mathrm{S} / \mathrm{N}$ 比が小さいなど欠点があるが, 周波

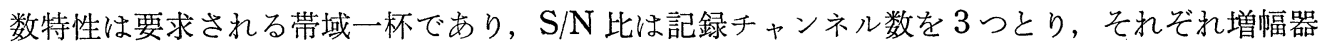
の倍率を変えて用いることにより改善した.このためチャンネル数に余裕が無く, 地震計は上 下動だけを用いた。

使用した地震計，レコーダーの特性を Table 2,3 に示す. 地震計は信号ヶーブル以外は耐 寒性は考慮していない.レコーダーは DR (Direct Recording) 方式でテープスピードが $0.2375 \mathrm{~mm} / \mathrm{s}$ で C-90 型のカセットテープで 6 日強, 連続記録が可能である. レコーダー, 時 
Table 2. Characteristics of transducer.

\begin{tabular}{l|l}
\hline \hline Type & Katsujima PWK-110 V \\
Natural frequency & $1.0 \mathrm{~Hz}$ \\
Outer case dimensions & $28 \mathrm{~cm} \times 22 \mathrm{~cm} \times 26 \mathrm{~cm}$ \\
Moment of inertia of the pendrum & $2.0 \times 10^{4} \mathrm{gcm}^{2}$ \\
Sensitivity & $2.07 \mathrm{~V} / \mathrm{cm} / \mathrm{s}$ \\
Coil resistance & $1.6 \mathrm{k} \Omega$ \\
External circuit resistance & $10 \mathrm{k} \Omega$ \\
Damping constant & 0.67 \\
\hline
\end{tabular}

Table 3. Characteristic of data recorder.

\begin{tabular}{l|l}
\hline \hline Type & Katsujima CJI-N \\
1. Recorder and amplifier & \\
Recording mode & Direct analogue recording \\
Tracks/channels & $4 / 4$ \\
Tape speed & $0.2375 \mathrm{~mm} / \mathrm{s}$ \\
Input impeadance & $30 \mathrm{k} \Omega$ \\
Gain of amplifier & $30,40,50,60,70$ and $80 \mathrm{~dB}$ \\
Frequency responce & $0 \mathrm{~dB} \pm 1 \mathrm{~dB}$ from $0.3 \mathrm{~Hz}$ to $30 \mathrm{~Hz}$ \\
Signal-to-noise ratio & $30 \mathrm{~dB}$ or more \\
Supply voltage & DC $12 \mathrm{~V}$ \\
Dessipation & $35 \mathrm{~mA}$ \\
Clock & Crystal oscillator \\
Time base & $\pm 5 \times 10^{-7}$ \\
Accuracy & Second and minute marks with BCD serial code of \\
Output & day, hour and minute \\
Supply voltage & DC $12 \mathrm{~V}$ \\
Dissipation & $75 \mathrm{~mA}$ (Display ON), 20 mA (Display OFF) \\
\hline
\end{tabular}

計部とも IC の低温時の特性は MIL 規格のものを用いれば保障されるが，使用する磁気テー プは低温時の保障がなく，レコーダーの磁気テープ装着部の上にパネルヒーターをつけ,さら にレコーダーを保温箱に格納した。保温箱内には燃料亜鉛電池も設置し，この電池からの発熱 で, 保温箱内の温度を, 設置時では外気温の $-20^{\circ} \mathrm{C}$ 近くから, $0^{\circ} \mathrm{C}$ までたかめ, 一週間はそ のままに保てた。

各観測点に用いたレコーダーには時計が内蔵されているが，時刻の較正は 1 台の親時計を用 いて行つた. Table 4 にその親時計の特性を示す. 爆破点で用いた時計の較正も, 同じ方法で 行つた.

\section{2-3. 再生計器}

得られた記録の再生は室内で行うため低温については考慮する必要がない。記録したカセッ トテープの再生は市販のカセットデッキを 4 チャンネルに改造したものを使用した。これから 
Table 4. Characteristic of time calibrator.

\begin{tabular}{|c|c|}
\hline $\begin{array}{l}\text { Type } \\
\text { 1. Recorder } \\
\text { Recording mode } \\
\text { Tracks/channels } \\
\text { Tape speed } \\
\text { Supply voltage } \\
\text { Dissipation } \\
\text { 2. Time code generator } \\
\text { Time base } \\
\text { Accuracy } \\
\text { Output } \\
\text { Supply voltage } \\
\text { Dissipation } \\
\text { Others } \\
\text { External clock number } \\
\text { JJY filter }\end{array}$ & $\begin{array}{l}\text { Katsujima CJI-C } \\
\text { Direct analogue recording } \\
4 / 4 \\
0.2375 \mathrm{~mm} / \mathrm{s} \\
\text { DC } 12 \mathrm{~V} \\
200 \mathrm{~mA} \\
\text { Crystal oscillator } \\
\pm 2 \times 10^{-8} \\
\text { Second and minute marks with } \mathrm{BCD} \text { serial code of } \\
\text { day, hour and minute } \\
\text { DC } 12 \mathrm{~V} \\
300 \mathrm{~mA} \\
\text { Set up by digital switches } \\
f_{c}=1.6 \mathrm{kHz}, Q=5\end{array}$ \\
\hline
\end{tabular}

の出力信号は質を下げない様に FM 録音方式のデータレコーダーを用い て，データの編集を行つた．可視記録 の再生は, 再生スピードが原記録ス ピードの 100 倍になるので, 電磁オシ

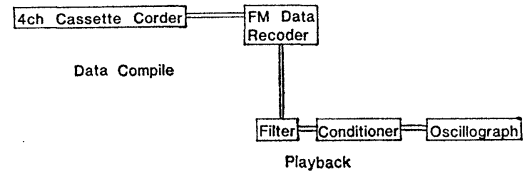

Fig. 2. Block diagram of play back system. ログラフを用い,フィルター, コンディショナー (増幅器) を通し行つた. 再生時のブロック ダイヤグラムを Fig. 2 に示す.

\section{2-4. 爆 破 点}

Shot-1 は水深 $110 \mathrm{~m}$ の海水中で薬量 1 ton で行つた. Shot-2 は雪氷ボーリングを実施し,

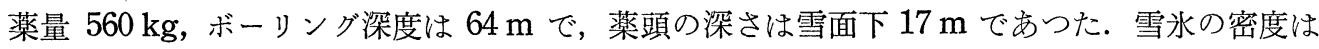
深さ $41 \mathrm{~m}$ で $0.69 \mathrm{~g} / \mathrm{cm}^{3}, 60 \mathrm{~m}$ で $0.81 \mathrm{~g} / \mathrm{cm}^{3}$ であつた.

\section{3. 結果}

No. 5 の観測点で記録できなかつたことと, Shot-2 の時に No. 6 の時計がカウントミスを し，較正することが湟とんど不可能だつたこと，時計のトラブルで Shot-2 の爆破時刻を得る ことができなかつたこと，を除くと，観測は所期の目的を達した。

\section{3-1. 波形}

Shot-1, Shot-2 より得られた記録を. Fig. 3，4 に示す. Shot-1 と Shot-2 の波形を比較す ると周波数成分に大きな違いが見られる.それぞれの記録の初動から 2 秒間汪どの部分のスペ 


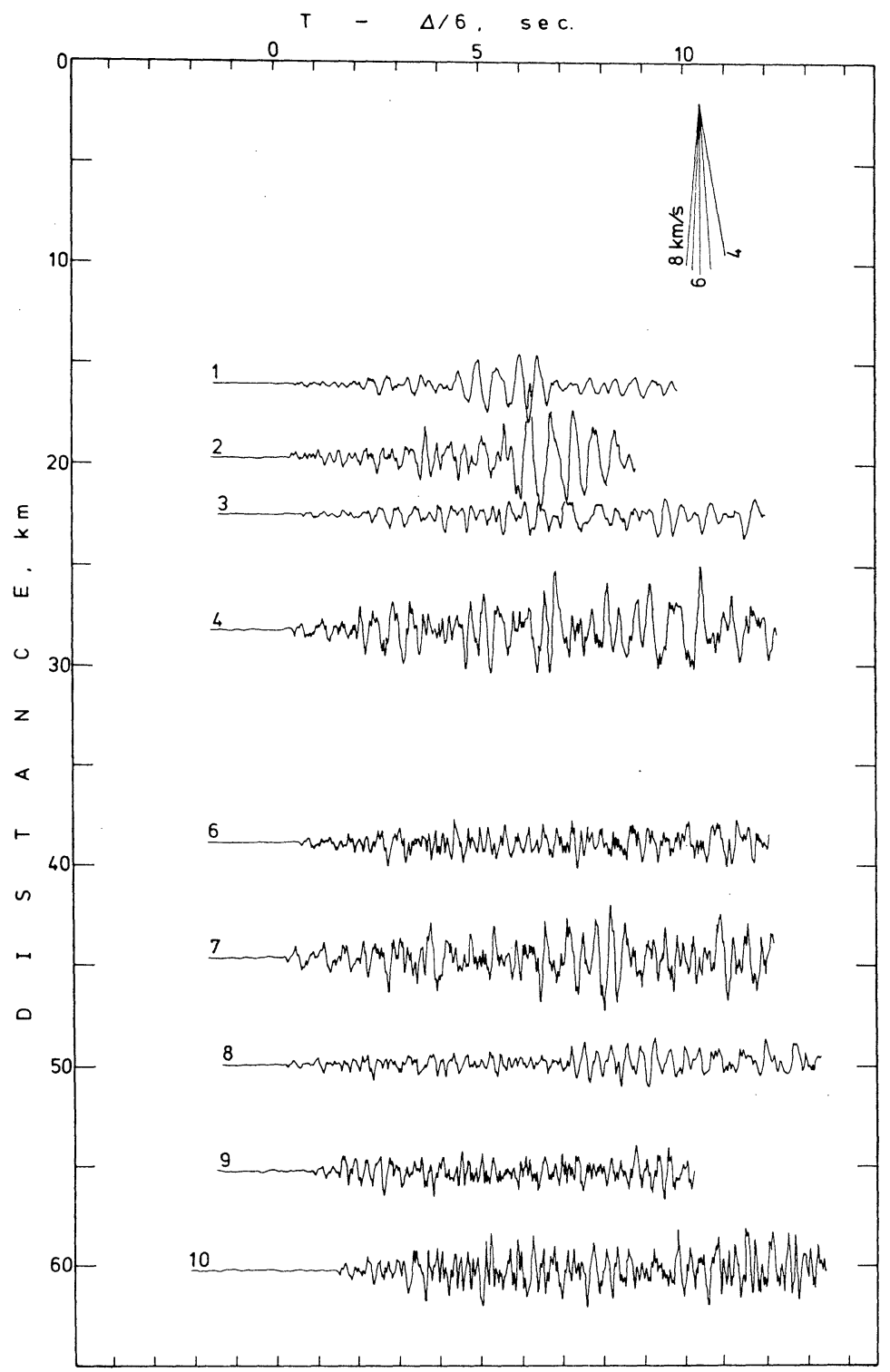

Fig. 3. Seismogram of SHOT-1. The numbers show the station corresponding with the station numbers in Fig. 1.

クトルを Fig. 5, 6 に示す. 戝から明らかなように Shot-1 の場合, 卓越周波数は $2 \sim 4 \mathrm{~Hz}$ になつている．爆破点の媒質の違い，つまり水中と水雪爆破に起因寸ると思われるが，今後の 調査課題としておく. Shot-1 の場合には顕著な後続波が見られるが，観測点間で対応がつか ないので，解析には使用していない。 


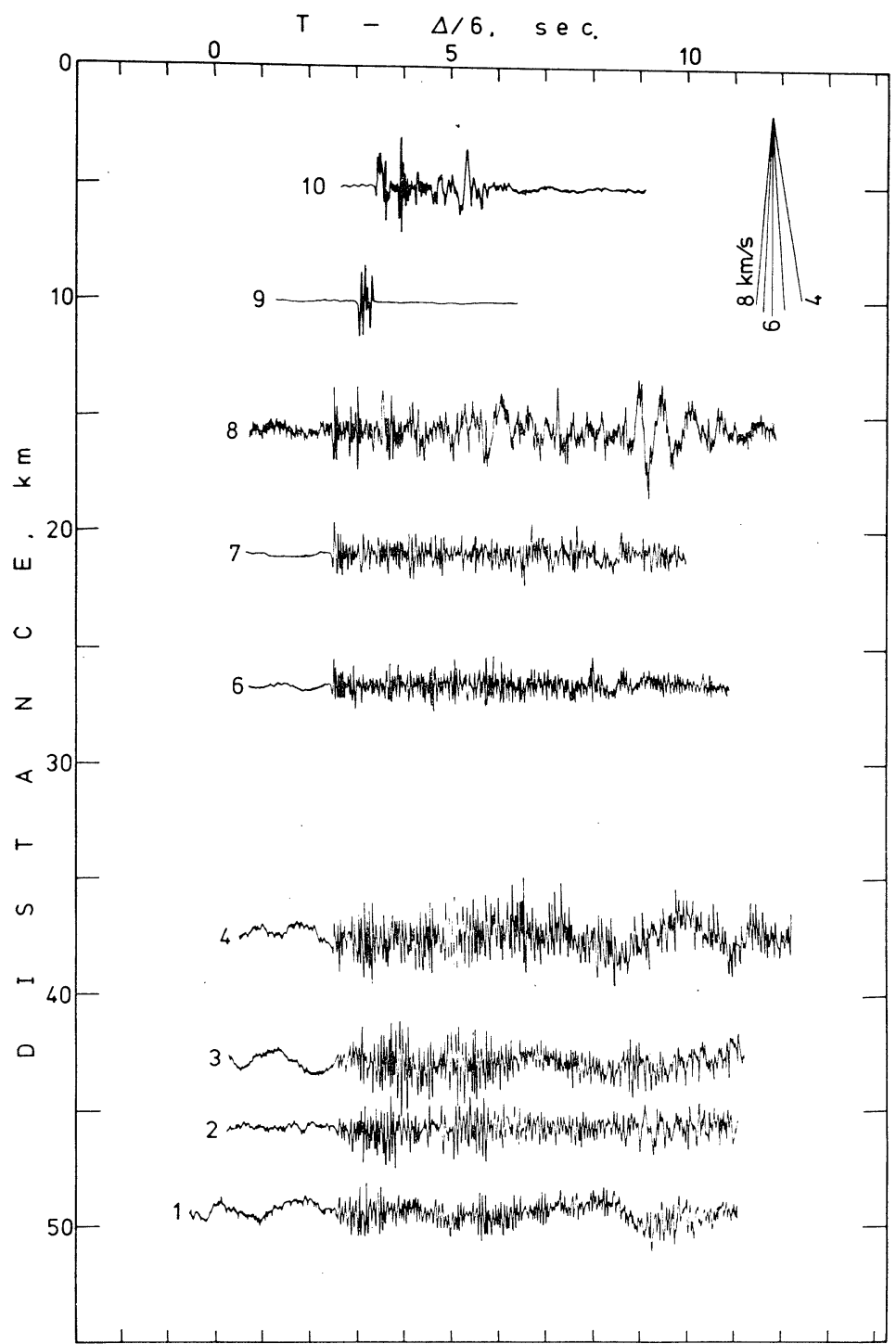

Fig. 4. Seismogram of SHOT-2. The numbers show the station corresponding with the station numbers in Fig. 1.

\section{3-2. 振幅}

Fig. 7, 8 には得られた記録の振幅と震央距離との関係を示す. 両図からわかるように, Shot-2 より得られた振幅は, Shot-1 の結果に比べて約 1 桁小さい. 薬量が半分になつている ことはあるが，雪氷中の爆破の効き方が悪いことを示している．効き方の悪さは爆破点付近で もほとんど体感の振動を感じなかつたほどである.この爆破の効率改善は南極におケる人工地 震観測の今後の大きな課題の一つである. 


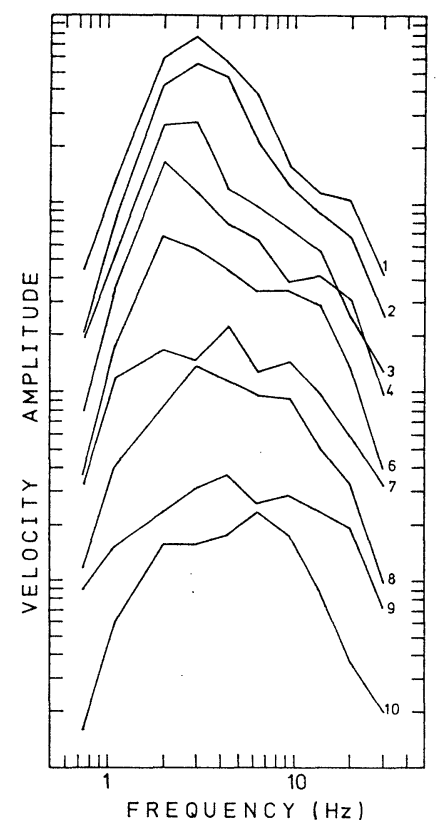

Fig. 5. Spectrum of initial $P$ phase of SHOT-1. The numbers show the station corresponding with the station numbers in Fig. 1.

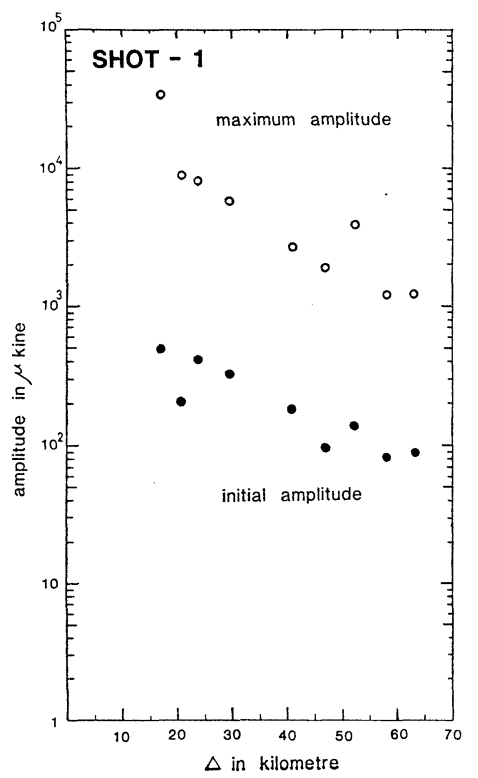

Fig. 7. Amplitude of initial phase of half cycle and maximum amplitude on one cycle versus epicentral distance in SHOT-1.

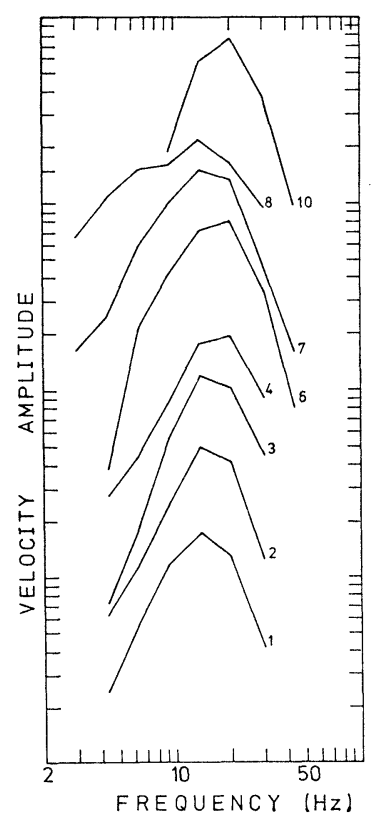

Fig. 6. Spectrum of initial $P$ phase of SHOT-2. The numbers show the station corresponding with the station numbers in Fig. 1.

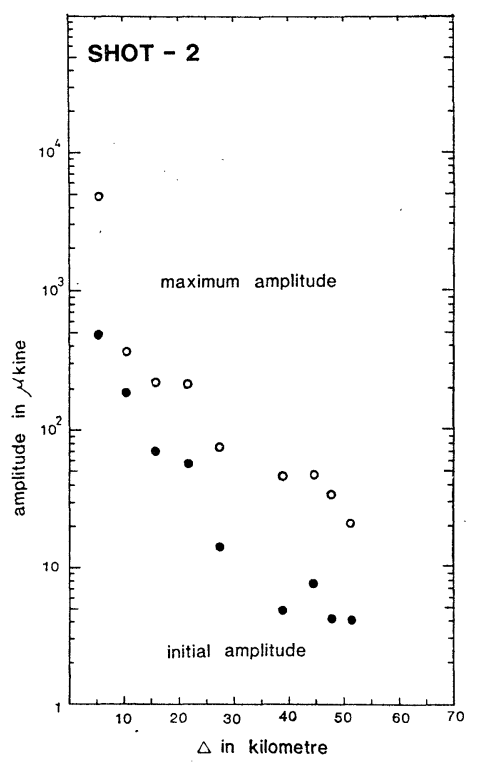

Fig. 8. Amplitude of initial phase of half cycle and maximum amplitude of one cycle versus epicentral distance in SHOT-2. 


\section{3-3. 構 造}

Fig. 9 上部に走時図を示す. Shot2 の方は時計のトラブルで爆破時刻を 知ることができないので, 補正量 $\alpha$ を 加えて示した. Shot-1 の No. 7,8の 走時を地殼上部からの屈折波とする と，見かけ速度が大きくなり，Shot-2 との差が大きくなりすぎ，境界面をか なり傾ける必要がある. No. 7, 8 の 初動が下部地殼からの屈折波だとし， $\mathrm{P}$ 波速度を $7 \mathrm{~km} / \mathrm{sec}$ とすると，その 深さは $5 \mathrm{~km}$ 前後になり, 上部地款の 厚さがかなり薄くなつてしまい，厚さ だけからみれば海洋地殼に近い性質の ものと推定される. しかし，これ以上 のデータがないので, この 2 つ初動 は構造決定からは省いた。

Shot-1 \& Shot-2 む No. 9, 10 の 観測点の走時が他の点に比べて遅れて いる.これは表層が厚くなつているた めと解釈した，構造決定には観測值か ら観測点下の氷床の厚さ〔ISHIDA (1972)] の相当分の走時だけ引き, 観 測点はすべて岩盤上にあるとした．雪氷内の P 波速度は ETO (1971) の極点旅行の際に行われ た小規模爆破の結果を用いた．Fig. 10 に氷床の厚さの断面を示したが，この附近の水床下の 基盤岩表面の標高をみるとほぼ海抜 $0 \mathrm{~m}$ になるので, 地震計の高度は全て $0 \mathrm{~m}$ として解析を 行つた.

Shot-1 からの構造は水平成層であるとして求めた場合の走時 $6.1 \mathrm{~km} / \mathrm{s}$ を用いて，それぞれ のデータより各観測点下のタイム・タームを求めた．そして，その值をもとにして Shot-2 の データより, No. 7, 8, 9, 10 抢よび Shot-2 下のタイム・タームを求め, その結果をならし て, 構造におきかえた。このようにして求めた構造を Fig. 9 下部に示す. 地殼の表層の P 波 
速度は不明なので, $4 \mathrm{~km} / \mathrm{sec}$ また $5 \mathrm{~km} / \mathrm{sec}$ と仮定し，それぞれの場合について構造をまと め, 重ね合わせ, 二つのモデルで違いのある部分を斜線で示し構造の概略を示した.この結果 No. 4 6 の付近で, 表層がうすくなり, Shot-2 の付近ではこの表層が厚くなつていると推定 した.

\section{5. 結 論}

昭和基地東方の大陸上で人工地震実験を行つたが, $500 \mathrm{~m} \sim 1 \mathrm{~km}$ 厚さの表層の存在を示す結 果が得られた.今まで南極大陸上で行われた主な人工地震実験の場所とその結果を Fig. 11 に 示す. Fig. 11 に示されているように, 東南極と西南極の構造の間には大きな差がみられる. すなわち, 多数の実験が行われている西南極では, 表層の存在が示されているのに対し, 東南 極楯状地での結果には表層の存在が示されず，氷床の下に直接上部地殼が存在することになつ ている.

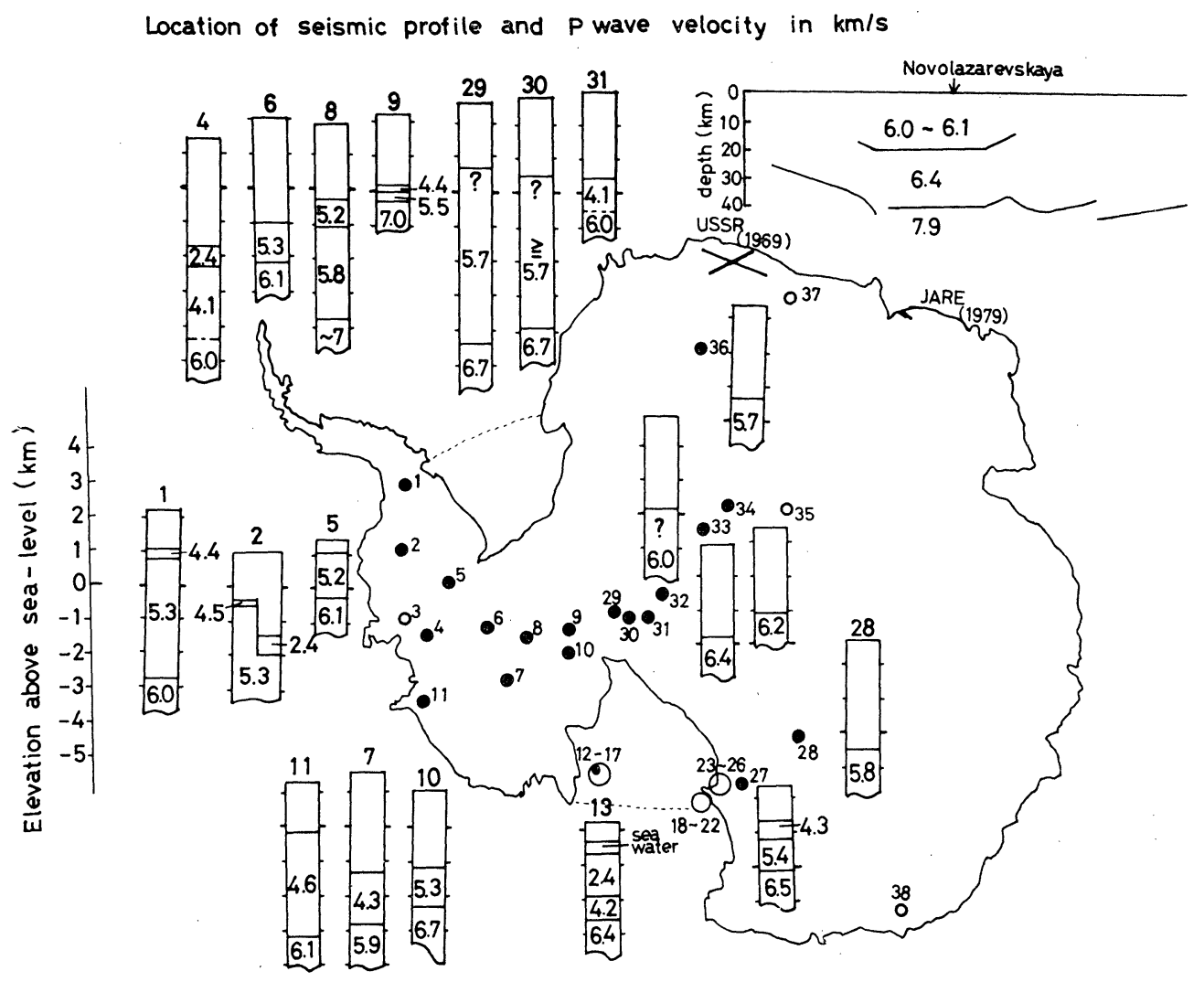

Fig. 11. Location of seismic profile operated in Antarctica and velocity columns of $P$ wave velocity in $\mathrm{km} / \mathrm{s}$. The numbers of columns are corresponding the numbers of profile [After Bentley and Clough (1972) and KogaN (1972)]. 
一方，今回の結果は表層の存在を推察できる結果になつた。この事実は，東南極楯状地とは いえ，今回の測線のように，その周辺部で，しかも基盤地形が盆地状を呈するような地域には 表層が存在することを示していると考光られる，今後，実験の積み重ねにより，昭和基地を中 心とした地域の基盤構造のより精密な決定を行い, さらに南極大陸の地下構造の解明が期待さ れる.

謝 辞

本実験は第 20 次南極地域観測隊夏隊の最大のオペレーションであつた. 吉田栄夫隊長以下 全隊員の協力により，所期の目的が達成され，感謝の念に耐兄ない。特に，64 $\mathrm{m}$ の孔を 19 日 で掘つた原田道昭隊員（現在：早稲田大学理工学部）の苦労は大変だつた。

計画や準備の段階から有益な助言を賜りつづけた。極地研究所地学専門委員会の浅田 敏委 員長以下, 浅野周三 (東京大学地震研究所), 青木治三 (名古屋大学), 高木章雄 (東北大学) 各委員にも厚く御礼申上げる.

\section{文献}

Bentley, C. R. and J. W. Clough, 1972, Antarctic Subglacial Structure from Seismic Refraction Mearurements, Antarctic Geol. Geophys., ed., AdIE, Oslo, 683-691.

Ето, T., 1971, Seismic studies during the JARE South Pole Traverse 1968-69, Scientific Rep. Special Issue No. 2, 115-124.

伊神 煇・一ノ瀬洋一郎・原田道昭・神沼克伊, 1980 , 南極に招ける人工地震観測の概要, 南極資料. IsHIDA, T., 1972, Glaciological Research Program in Mizuho plateau-West Enderby Land, part 1, 1969-1971, JARE Data Rep., No. 17, 217 pp.

Kogan, 1972, Results of Deep Seismic Sounding of the Earth's Crust in East Antarctica, Antarctic Geol. Geophys., ed., ADIE, Oslo, 485-489. 